\title{
Perspectives on the Concept of Economics
}

\section{Gomes O*}

Lisbon Accounting and Business School (ISCAL-IPL) \& Business Research Unit (UNIDE-ISCTE/IUL), Portugal

*Corresponding author: Gomes O, Lisbon Accounting and Business School (ISCAL-IPL) \& Business Research Unit (UNIDE-ISCTE/IUL), Portugal, Tel: 351933420915; E-mail: omgomes@iscal.ipl.pt

Received date: April 27, 2016; Accepted date: April 28, 2016; Published date: May 02, 2016

Copyright: (C) 2016 Gomes O. This is an open-access article distributed under the terms of the Creative Commons Attribution License, which permits unrestricted use, distribution, and reproduction in any medium, provided the original author and source are credited.

\begin{abstract}
Scientific knowledge covers all aspects of life. Economics, in particular, addresses the choices, the behavior and the interactions of human beings in a wide range of circumstances, and even the most unsuspected themes can be subject to the scrutiny of this science. In this brief note we discuss what Economics is all about, resorting to a small set of contributions published in the recent past in a top Economics journal, namely the Journal of Economic Perspectives.
\end{abstract}

Keywords: Economics; Civilizations; Philosophy; Neoclassical principles

\section{The Oikonomia}

Economic affairs are of primary importance in any organized human society. Hence, it is with no surprise that one is able to find in ancient civilizations the first systematic and coherent writings about economic relations and their implications. In particular, the Greek civilization and some of its most outstanding philosophers (e.g., Aristotle, Plato or Xenophon) engaged in a prolific reflection concerning how individuals produce, trade and consume to satisfy the respective needs. A journey through the narratives of such pioneer thinkers may help in understanding what modern Economics is truly about.

As many other contemporary terms, the word 'economy' has its origins in ancient Greece. The original word, 'oikonomia', might be loosely translated as the management of the household, an idea that effectively constitutes a good foundation to begin discussing the organization and evolution of economic relations. According to Leshem [1], though, meaningful differences exist between the concerns of modern Economics and the archaic notions associated with the concept of 'oikonomia. While today's Economics might be roughly defined as the science that studies the efficient allocation of scarce resources in order to satisfy human needs and assist in maximizing utility, the original idea had some twists that are worth highlighting.

First, at that time scarcity was not interpreted as a central concern. If available resources are to be wisely and parsimoniously used, they will exist in sufficient abundance to satisfy all human needs. This leads us directly to the second issue, which is related to the ethical principles that the philosophers of ancient Greece thought should guide economic behavior. While ethical norms are not at the core of modern Economics, they were essential in the view of the 'oikonomia': the satisfaction of material needs was not seen as an end in itself and, therefore, the management of personal finance should be oriented to the avoidance of unnecessary luxuries.

The economic dimension was interpreted as an accessory to what truly matters in life. By carefully managing economic resources, households could secure their physical existence and generate a surplus, which could be used in what should effectively matter: the quest for knowledge and wisdom, and the participation in civic and political activities (which are meant to serve others and the society as a whole). The ethical dimension of the economic agent in the 'oikonomia' raises also the issue of rationality: modern Economics associates the concept of rationality to the ability to select between alternative choices given existing opportunity costs; a rational agent in the 'oikonomia', however, is the individual capable of understanding the auxiliary role Economics has in life and the central position philosophy and politics occupy.

Although the deepest roots of modern Economics can be traced back to the notion of 'oikonomia' as characterized above, one must stress that important differences exist between the contents of such notion and today's economic science. The idea of ethical allocation of abundant resources was replaced by the notion of optimal allocation of scarce resources; the virtuous search for extra-economic spiritual satisfaction was abandoned in favor of a concept of utility maximization where utility may come from any material or immaterial entity that satisfies human needs; the association between rationality and frugality was substituted by a view on rational behavior attached to the optimization of decisions and actions.

\section{The Science of Rational Behavior}

It took two millennia after the advent of the Greek civilization for economic thought to start gaining a truly scientific status. With classical social philosophers (e.g., Adam Smith, David Ricardo, John Stuart Mill, Jean-Baptiste Say), national strategies and policies oriented to the creation of wealth and to guarantee material prosperity for sovereign states became the focus of a strand of thought that acquired the designation of political economy. Political economy dealt with how governments can create the conditions that allow states to benefit from specialization in production and from the liberalization of trade.

In the nineteenth century, political economy gradually gave place to a broader field of study that encompassed not only themes of the national economy, but also subjects related to individual decisionmaking and to the organization of markets. The marginalist revolution, led, among others, by Carl Menger and Stanley Jevons, culminated in the influential contribution of Alfred Marshall, who in his famous 
works Principles of Economics, synthesized the object of Economics by combining the concerns on wealth creation with the observation and study of human behavior.

It is precisely with Alfred Marshall that the use of the term Economics is generalized. The transition between political economy to Economics marks the birth of a new science, a social science deeply rooted on rigorous mathematical analysis and in no way ideologically or politically oriented. What does this science deal with in current days and what subjects should be of interest to it? This is a hard question, as the difficulty in rigorously defining Economics suggests. According to Backhouse and Medema [2], any concise definition of Economics will be inadequate given the wide range of subjects it embraces, the multiplicity of techniques it employs, and the difficulties in establishing frontiers with other social and human sciences.

Despite the difficulties, one can always adopt a trivial and relatively general definition, as those frequently appearing in introductory textbooks: Economics studies the efficient allocation of scarce resources by rational agents at the individual, social, national and global levels. Although short, this definition comprises most of the essential ingredients of what Economics is about; it deals with the human ability to choose, with the constraints that choices involve and with the multiple dimensions of the decision-making process.

Economics is today an extremely active field of research. Given the comprehensive array of the subjects it studies and the unique rigorous approach it adopts to discuss matters on human behavior and interaction, this scientific field was able to stand out relatively to other fields of knowledge, as highlighted in Fourcaude et al. [3]. On one hand, it stands out as the most formal of the social sciences, capable of interpreting reality through a collection of quantitative and logical models, rather than constraining itself to a discursive reasoning as other social sciences do; on the other hand, it apparently also has a particular role within the hard sciences, because it is allegedly the only science capable of identifying universal principles originating on complex human behavior.

Despite its virtuosities, claiming a superiority status for Economics in the universe of scientific fields is either humble or wise. Most of the progress of science occurs through interdisciplinary cooperation and if economists reject this cooperation they will not be able to generate the knowledge they could potentially create to better serve the academy and the society as a whole.

\section{Avenues for the Future}

Economics is taught in universities and what Economics truly is relates to the outcome of the education process, namely in the most influential North-American faculties. In Colander [4] a thorough examination of the opinions of students in the top Economics faculties is undertaken. Students diverge in terms of their understanding of what this science effectively is, what it studies and which subjects should concern it the most. This divergence unveils that teaching traditions and teaching perspectives are fundamental in shaping the minds of the new economists. Concepts as the rational expectations hypothesis or money illusion have different relevance for students at different major schools.

Having a detailed notion about what is being taught helps in understanding what the future of Economics will be. While some top universities have clear distinctive views on the direction Economics should follow (with some emphasizing neoclassical principles, others giving more importance to institutions, norms and conventions, and yet others insisting in the central role of human behavioral traces), in general the views on Economics continue to be general and pervasive, reaching a large number of relevant subjects.

A common worry shared by students of Economics relates to the excessive focus on mathematical modeling. Unarguably models are important to organize ideas and thoughts, but Economics needs to be much more than this. It has to do with creativity and reasoning and, thus, in order for a stronger and more complete Economics paradigm to emerge, creativity and reasoning should accompany technical tools in the classroom.

The future of Economics and the avenues the respective studies will follow may be discussed in multiple perspectives. An interesting account about the future of this science is offered by Thaler, who identifies six possible meaningful trends. These trends essentially sophisticate the economic agent as it is commonly perceived in the profession: the homo economicus, a useful notion that reflects the principle of rationality that is incorporated in most economic models, will give place to a more organic view of human behavior. Since economists have already understood how a rational thinker acts, it is time to look beyond rationality and to investigate how actual behavior in concrete economic and social scenarios triggers outcomes that, although observed in practice, are incompatible with the current Economics orthodoxy.

The trends mentioned by the referred author are the following: first, recognizing that the notion of a hyper-rational agent is exaggerated from the point of view of understanding real phenomena; Economics will progress in the direction of a less strict rationality concept. Second, associated with the previous argument, economic analysis will progressively give more relevance to learning processes and one should recognize that learning does not lead, in every occasion, to equilibrium of full knowledge. Third, increased attention will be given to the persistence of heterogeneous behavior. Fourth, the mental processes underlying human choice will have a more relevant role in economic models. Fifth, the theory will be able to discern between normative analysis (how agents should behave) and descriptive analysis (how agents effectively behave). Sixth, emotions will definitively enter the realm of Economics.

The above trends to be followed by Economics are inter-connected and represent an effort to turn this into a more applied and practical science. This does not mean that one should completely reject the Homo Economicus paradigm, according to which agents are rational, fast learners, behave optimally, and thus similarly to each other, and where emotions play no role. This was a useful paradigm to understand the structure of economic relations. However, as economic knowledge progresses one should go further and deeper. Human beings are not perfect computing machines: they have their idiosyncrasies, they need time to learn and they are often driven by emotions like "anger, hatred, guilt, shame, pride, liking, regret, joy, grief, envy, malice, indignation, jealousy, contempt, disgust, fear, and, oh yes, love" [5]. Adding these sentiments to the analysis of economic phenomena, with the tools that economists already have available can only expand the scientific frontier in Economics, allowing for a more in depth understanding of many observable facts.

In this note, one has made a brief, and with many gaps, journey through the meaning of Economics as a scientific discipline. It began as a description of household management; it evolved to the study of productive and trading activities within and between nation states; it 
then recovered the relevance of individual behavior and market interactions. Mainstream Economics is nowadays focused on how rational behavior promotes predictable outcomes, but a relevant shift of paradigm is occurring, as researchers engage in a deeper analysis of behavioral elements that escape the straightjacket of hyper-rationality that economists have imposed to themselves.

\section{References}

1. Leshem D (2016) What Did the Ancient Greeks Mean By Oikonomia. Journal of Economic Perspectives 30: 225-238.
2. Backhouse RE, Medema SG (2009) Retrospectives on the Definition of Economics. Journal of Economic Perspectives 23: 221-233.

3. Fourcaude M, Ollion E, Algan Y (2015) The Superiority of Economists. Journal of Economic Perspectives 29: 89-114.

4. Colander D (2005) The Making of an Economist Redux. Journal of Economic Perspectives 19: 175-198.

5. Thaler RH (2000) From Homo Economicus to Homo Sapiens. Journal of Economic Perspectives 14: 133-141. 